\title{
State of oncology nursing training and practice in a southwestern Nigerian teaching hospital
}

\author{
Prisca Olabisi Adejumo ${ }^{1}$, Kehinde Funmilola Akinyemi*2, Agnes N. Anarado ${ }^{3}$, Chizoma M. Ndikom ${ }^{1}$, Beatrice M. \\ Ohaeri $^{1}$, Omowumi O. Okedare ${ }^{4}$, Odinaka Benardette Ani ${ }^{1}$, Abimbola O. Oluwatosin ${ }^{1}$ \\ ${ }^{1}$ Department of Nursing, Faculty of Clinical Sciences, College of Medicine, University of Ibadan, Ibadan, Nigeria \\ ${ }^{2}$ Clinical Nursing Department, University College Hospital, Ibadan, Nigeria \\ ${ }^{3}$ Department of Nursing Sciences, Faculty of Health Sciences \& Technology, College of Medicine, University of Nigeria, Enugu \\ Campus, Nigeria \\ ${ }^{4}$ Department of Epidemiology and Medical Statistics, Faculty of Public health, University of Ibadan, Ibadan, Nigeria
}

Received: April 8, 2021

DOI: $10.5430 /$ jnep.v11n9p68
Accepted: April 27, 2021

Online Published: May 27, 2021

\begin{abstract}
Background and objective: Oncology nursing is a recognized nursing specialty globally but it is yet to be a stand-alone specialty in any accredited degree awarding tertiary institution in Nigeria as at the time of this write up. In most of the hospitals in Nigeria, non-specialist oncology nurses who learn on the job care for the cancer patients. Hence, the urgent need to conduct this study, which aimed to examine the state of oncology nursing training and practice in Nigeria.

Methods: A descriptive, cross-sectional study was used to assess 171 nurses' socio-demographic data, nature of their oncology training, and competency level using a semi-structured questionnaire.

Results: Only $3(1.8 \%)$ of the respondents claimed they had a degree in oncology nursing and $89.9 \%$ had no formal training in oncology. Few of the respondents (13.5\%) rated themselves as experts in oncology nursing practise. Majority of the respondents see the state of oncology nursing practise as very poor with the major challenge being none availability of oncology nursing training institution.

Conclusions and implication for study: With the increasing prevalence of cancer in Nigeria and rise in number of new cases daily, there is need for an established programme to train health care professionals especially nurses to combat its increasing rate. There is need for provision of oncology nurse specialist training to improve level of education and skills in order to offer appropriate care to clients living with cancer and improve patient's outcome of survival ultimately enhancing their quality of life.
\end{abstract}

Key Words: State, Oncology nursing, Oncology training, Competency, Practice

\section{INTRODUCTION}

Cancer constitutes a major cause of death worldwide; responsible for 1 in 6 deaths. ${ }^{[1]}$ It was responsible for 9.6 million deaths worldwide and about $70 \%$ of these deaths occurred in developing countries. ${ }^{[1,2]}$ It accounted for 72,000 deaths in Nigeria every year, with an estimated 102,000 new cases of cancer annually with a high mortality prevalence ratio.
The increasing prevalence of cancer in un-industrialized nations mirrors a wider transition in the universal burden of disease from infectious diseases to increased incidence in non-communicable diseases (chronic illness). ${ }^{[3]}$

The Nigerian Federal Ministry of Health established a National Cancer Control Programme with a Cancer control

\footnotetext{
*Correspondence: Kehinde Funmilola Akinyemi; Email: kennyenny1981@gmail.com; Address: Clinical Nursing Department, University College Hospital, Ibadan, Nigeria.
} 
Plan for 2018-2022 in recognition of cancer being a main cause of morbidity and mortality. ${ }^{[2]}$ One of the strategies designed to achieve the strategic goals is to focus on the priority areas, strategies are to increase the health care providers' knowledge on standards of care for effective management of cancer.

Nurses in Africa form the largest portion of the health care professionals. They are, therefore, a unique choice to lead the cancer control agenda because they are also the first point of contact with communities in Africa. Nurses are strategically placed to understand more than anybody else how the population interacts with the social, economic, and political environment. ${ }^{[4]}$ Nurses can design and deliver innovative, culturally acceptable, low-price cancer control packages, by identifying and closing the gaps on missed opportunities. Universally, nurses are considered very important in all phases of cancer control and management due to their role on the quality-ofcare outcomes which is greatly influenced by specialized training in oncology nursing. ${ }^{[5]}$ Nurses are also known for their holistic approach in caring for these patients. ${ }^{[6]}$ However, in Nigeria and some portions of Africa, there is no formal oncology training for nurses especially in institutions of higher learning to meet the current burden in cancer care in Nigeria specifically and other parts of Africa in general.

The specialized training for qualified nurses in most of the African countries where available mainly follows situations dictated by disease patterns and availability of resources. Majority of nurses learn to deal with complexities of cancer management on the job. Lack of training is worsened by competing health care priorities. ${ }^{[7-9]}$ Though cancer is one of the leading causes of death in Africa, ${ }^{[10]}$ opportunities for specialised or advanced education in cancer care nursing are few and far apart in African nations in spite of their care including palliative, effective physical and psychological care for patients. ${ }^{[11]}$ However, the effectiveness of care is reliant on the nurses' acquired knowledge and training skills to provide expert oncology nursing care according to Jenerette and Leak, ${ }^{[12]}$ and expanded roles. ${ }^{[13-15]}$

Some African countries are at different stages of developing their country specific cancer curricular. ${ }^{[10]}$ Kenya has oncology nursing programmes offered to nurses at Masters and Diploma levels. ${ }^{[4]}$ The most robust formal cancer nursing education programs in African continent can be seen in South Africa. Nigeria being the giant of Africa is yet to have an established, accredited, formal stand-alone oncology nursing specialty in any of its universities. However, there is an hospital-based school of oncology nursing that offers a one-year diploma training.

Therefore, there is an urgent need to assess the state of on- cology nursing training and practice in a Southwest Nigerian Teaching Hospital which is the laboratory for the Premier University.

\section{Aim}

The goal of this study was to examine the state of oncology nursing training and practice in a teaching Hospital in Southwestern part of Nigeria. The purposes were to: assess the training that the nurses working in oncology wards have acquired, assess their skills and competency, and identify how to improve the quality of oncology nursing care. Findings from this study will provide baseline information for a larger study involving the six geopolitical zones of Nigeria and if possible a larger multi country study in Africa.

\section{MeTHODS}

\subsection{Design and setting}

The study used a cross sectional, descriptive design to examine the state of oncology nursing practise in a Southwestern Teaching Hospital in Nigeria. The study involved registered nurses working in various oncology wards and unit of the premier Hospital, University College Hospital (UCH), Ibadan, Nigeria.

The $\mathrm{UCH}^{[16]}$ was established by an August 1952 Act of Parliament in response to the need for the training of healthcare professionals for the country and the West African SubRegion. The Hospital was tactically located in Ibadan, then the largest city in West Africa which is also the location of the first University in Nigeria. The UCH was originally commissioned with 500-bed spaces. Presently, the hospital has 1,000 bed spaces and 200 examination couches with occupancy rates ranging from $65 \%-70 \%$. Most of the nurses working in the oncology unit of the hospital learnt on the job.

\subsection{Sample size and sampling technique}

Calculated sample size of 171 was obtained from the total number of nurses working in oncology centres, clinics and ward of UCH using Taro Yamane's formula. A purposive sampling technique was used to recruit willing and available participants from the oncology wards and clinics. Participants were eligible for this study if: (1) they were willing to participate in the study (2) have worked in oncology wards/unit for at least one year. Individuals were excluded if they had foreign formal oncology nursing training and have less than a year experience in oncology wards.

\subsection{Instrument and data collection}

Data were collected using semi-structured questionnaire which included closed-ended and open-ended questions. The questionnaire consisted of six sections namely: Section A 
about respondents' socio-demographic data, Section B regarding the nature of oncology training received by nurses, Information about nurses' practise and competency were in Section C, Nurses' view of appropriate educational preparation for oncology nurses and state of oncology nursing practise in Nigeria were in Sections D and E respectively while Section F sought information on the challenges facing oncology nursing practise in Southwestern Nigeria and how it can be improved upon.

Ethical approval was sought and obtained from Ethical Review Committee of University of Ibadan/University College Hospital. Questionnaires were self-administered and retrieved following due completion over the duration of one month.

\subsection{Method of data analysis}

Descriptive statistics with the aid of Statistical Package for Social Sciences (SPSS), version 20 was used to analyze

Table 1. Socio-demographic characteristics $(\mathrm{N}=171)$

\begin{tabular}{|c|c|c|c|}
\hline & & Frequency & $\%$ \\
\hline \multicolumn{4}{|l|}{ Age } \\
\hline Mean age & $35.81 \pm 8.31$ years & - & ----- \\
\hline Duration of working in oncology unit (in month ) & $30.15 \pm 22.40$ months & - & ---- \\
\hline \multicolumn{4}{|l|}{ Gender } \\
\hline Male & & 30 & 17.5) \\
\hline Female & & 141 & $(82.5)$ \\
\hline \multicolumn{4}{|l|}{ Highest academic qualification } \\
\hline Diploma/HND & & 37 & $(22.0)$ \\
\hline B.Sc./BNSc & & 127 & $(75.6)$ \\
\hline M.Sc/MSN & & 4 & $(2.4)$ \\
\hline \multicolumn{4}{|l|}{ Professional qualifications } \\
\hline $\mathrm{RN}$ & & 33 & $(20.5)$ \\
\hline RM & & 3 & $(1.9)$ \\
\hline $\mathrm{RN} / \mathrm{RM}$ & & 124 & $(77.0)$ \\
\hline \multicolumn{4}{|l|}{ Other professional qualifications } \\
\hline B.Sc. palliative care & & 2 & $(16.5)$ \\
\hline $\mathrm{OHN}$ & & 2 & (16.5) \\
\hline Paediatric nursing & & 2 & $(16.5)$ \\
\hline PHN & & 5 & $(50.0)$ \\
\hline \multicolumn{4}{|l|}{ Degree in oncology } \\
\hline Yes & & 3 & $(1.8)$ \\
\hline No & & 168 & $(98.2)$ \\
\hline \multicolumn{4}{|l|}{ Formal training in oncology } \\
\hline Yes & & 17 & $(10.1)$ \\
\hline No & & 152 & (89.9) \\
\hline \multicolumn{4}{|l|}{ Duration of training } \\
\hline 3-5 days & & 4 & $(30.8)$ \\
\hline 2-3 months & & 2 & $(15.4)$ \\
\hline 6-7 months & & 3 & $(23.1)$ \\
\hline 8 months & & 2 & $(15.4)$ \\
\hline 2 years & & 1 & $(7.7)$ \\
\hline 3 years & & 1 & $(7.7)$ \\
\hline
\end{tabular}

closed ended questions. Frequency, percentages, mean and standard deviation were used to summarize the data, and results were presented in tables and figures. Counts were used to summarize open ended questions which sought respondents opinions on state on oncology and challenges facing oncology nursing practice.

\section{RESUltS}

Results from the study shows a mean age of $35.81 \pm$ 8.31 years. Seventy-five percent of the respondents had B.Sc./BNSc. (Bachelor of Science/Bachelor of Nursing Science) as their highest level of education, while $77 \%$ had $\mathrm{RN} / \mathrm{RM}$ as their professional qualification. Also, $98.2 \%$ do not have a degree in oncology and $89.9 \%$ have never had any formal training in oncology. Respondents' sociodemographic characteristics are detailed in Table 1. 
In terms of rotation in oncology wards, results from the study shows that the highest rotation of the nurses has been in oncology wards (23.4\%) followed by oncology clinic (13.6\%) while the least was in Palliative care unit $(8.2 \%)$ and Radiology unit $(8.2 \%)$. In the aspect of training that nurses in oncology had acquired, $68.6 \%$ (174) have received inservice/continuing education training, $20.1 \%$ (51) have received training at a conference/workshop, while the least was certificate courses which account for $11.4 \%$ (29) and this is presented in Figure 1.

Figure 2 illustrates the competencies and skills of nurses in oncology wards. Results from the study report that they were mostly skilled and competent in psychological and spiritual care (54.7\%); management of oncology pain and symptoms (54.4\%); and health promotion for cancer (53.3\%). The nurses however admitted incompetence in reconstituting and administration of IV cytotoxic drugs, screening for pap smear, mammography, Clinical breast examination (CBE) and obtaining sample for genetic testing at $32.9 \%, 36.9 \%$,
$27.1 \%$ and $33.3 \%$ respectively. Regarding their level of competency and skills, $60 \%$ of the nurses rated themselves as generalists in oncology as shown in Figure 3.

\section{Type of Training}

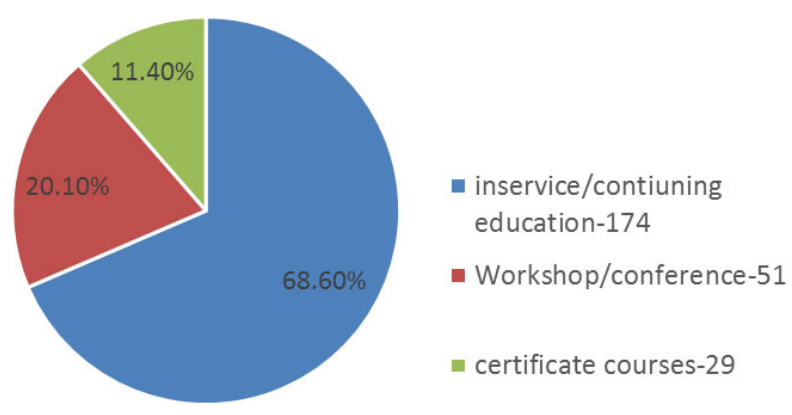

Figure 1. Type of training nurses in oncology wards have acquired (Multiple responses)

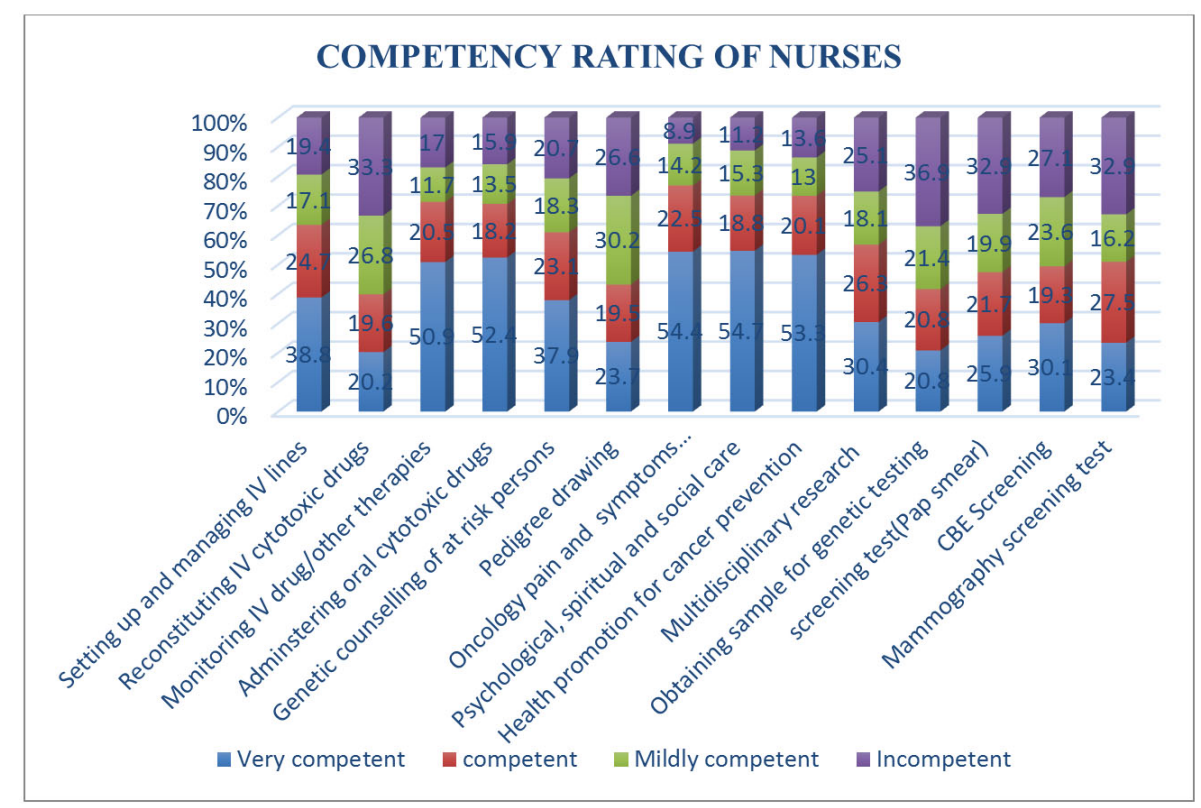

Figure 2. Competency rating of nurses working in oncology unit

In terms of their recommended minimum educational training for oncology nurses' preparation, $26.6 \%$ (93) responded that this category of nurses needs to be educated at the Masters level; while $23 \%$ (83) recommended 1st degree in Nursing while the least $7.8 \%$ (28) recommended Higher National Diploma in Nursing (see Table 2). It was also recommended by $98.1 \%$ respondents that Nursing and Midwifery council of Nigeria (NMCN) should conduct certification examination for nurses who want to practise as oncology nurses.
The state of oncology nursing in Nigeria was described by respondents as- poor $(n=38)$; upcoming profession $(n=21)$; not recognised as a specialty $(n=14)$; needing improvement $(n=12)$; and not satisfactory $(n=9)$. Among the challenges of oncology nursing training in Nigeria as recognized by respondents includes: no school of training $(n=22)$, lack of appropriate equipment $(n=16)$, lack of fund because training schools are very expensive $(n=21)$, and high shortage of oncology nurses in the country $(\mathrm{n}=2)$. Their suggestions for improving nursing in Nigeria include: provision of training 
centres and institutions that can offer oncology nursing (n $=25$ ), continuing education and workshop to update nurses on oncology care $(n=34)$, sponsorship for oncology nursing training $(n=25)$, and others stated that oncology nursing should be included in the school curriculum as a stand-alone specialty.

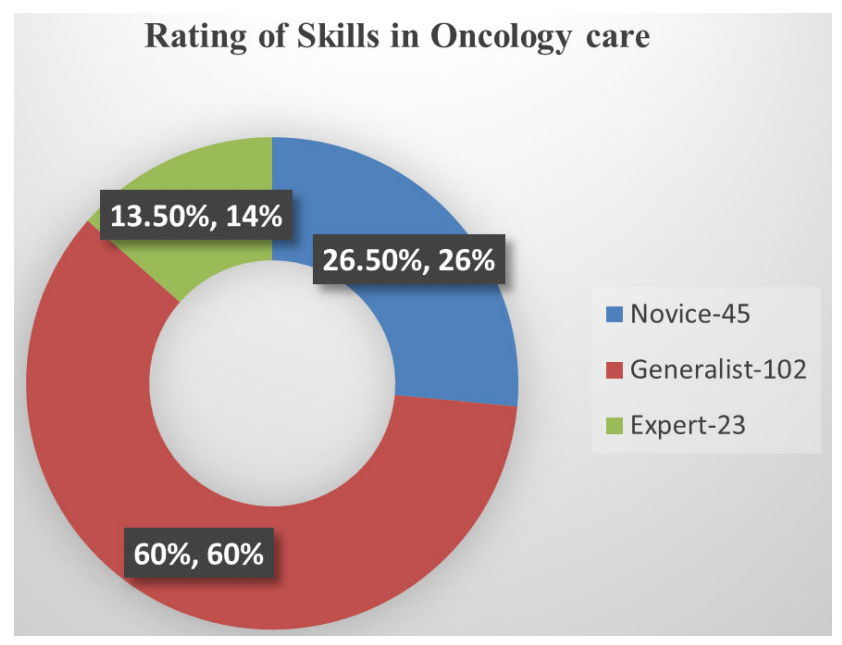

Figure 3. Self rating skill based on experience in oncology

Table 2. Participants' view on the minimum educational training preparation for Oncology nursing experts

\begin{tabular}{lll}
\hline Training for expertise & Frequency & Percentage (\%) \\
\hline M.Sc. oncology nursing & 96 & 28.0 \\
$1^{\text {st }}$ degree in nursing & 28 & 7.8 \\
HND & 28 & 7.8 \\
PGD oncology nursing & 78 & 21.6 \\
RN/RM certificate & 76 & 21.1 \\
\hline
\end{tabular}

\section{Discussion}

Nurses in every nation, including those in Africa, form the largest portion of healthcare workforce. ${ }^{[17]}$ As a part of the multidisciplinary team, nurses take a leading and important role in cancer control programmes locally and globally. Nurses in developing countries have a 'blueprint' to follow to address the challenges in cancer control. ${ }^{[17]}$ Oncology nurses contribute significantly to patient well being and clinical outcomes in addition to advancing nursing profession. The dramatic rise in cancer cases in Nigeria has further consolidated the important roles oncology nurses play in cancer prevention and treatment. ${ }^{[5]}$ However, shortage of qualified staff and lack of adequate education is stretching the already limited resources. These continuously serve as constraints in treating cancer efficiently in Nigeria. This is made even more visible as $98.2 \%$ of the respondents do not have a degree in oncology and $89.9 \%$ have never had any formal training in oncology. The picture is however similar across major developing countries where insufficient funding in the healthcare delivery system is the norm. ${ }^{[18]}$ Opportunities for post basic education in cancer care nursing are few. ${ }^{[19]}$ Nwozichi ${ }^{[20]}$ also asserts that while nurses are willing to engage in cancer care, they lack specific training in cancer care and chemotherapy. ${ }^{[5]}$ The study of Nwozichi et al. also states that oncology nursing specialization is not well established or available in Nigeria and this supports findings from this study. Findings from the present study is further buttressed by reports from Nursing World Nigeria, ${ }^{[21]}$ where it was stated that training and specialization continue to be inconsistent in relation to the specific content related to cancer during nursing diploma, undergraduate, and postgraduate training in Nigeria, with a gap between the practical and scientific preparation as well as the practice of specialized care. The importance of extending the qualification of health professionals should therefore be reinforced considering the figures which show that out of the many accredited Schools and Colleges of Nursing in Nigeria, none offers specialized oncology nursing program. Nevertheless, some African nations, such as South Africa and Kenya, have oncology nursing programmes at diploma and masters' levels. Tanzania, Zambia and Egypt have also made noteworthy progress in developing cancer nursing education. ${ }^{[4]}$ This therefore presents a dire need for nurses working in oncology sections in various hospitals in Nigeria to be properly educated and competent to meet the oncology patient's needs. Instead, the major form of training available in the respondents' institution were informal trainings, mostly comprising in-service training and continuing education, lasting approximately one week predominates. This finding is supported by findings from the study of Farmer and colleagues; Hanna \& colleagues, ${ }^{[22,23]}$ where majority of the nurses in cancer care learn on the job through experience, intuition, and short training and conferences. In many developed countries such as the U.S., nurses are required to complete a minimum number of continuing education hours in order to retain nursing certification. ${ }^{[24]}$ Due to generally lower levels of oncology-specific education for nurses in developing countries, the availability of continuing education offers an even more important opportunity for professional development. ${ }^{[24-26]}$ This must therefore be offered in a more robust way.

Nurses in this study also described the state of oncology nursing as poor, this is evident in the lack of established oncology training for nurses. Therefore, there is a need for nurses to be adequately equipped to manage the ravaging effects of cancer in Nigeria. In countries where there are established specialization training for oncology nurses, they focus on patients' assessment, symptom management, education and 
supportive care. In medical oncology, they play an important role in the administration of chemotherapeutic agents and are accountable for safe handling of drugs, laboratory data evaluation, drug dosage calculation using patients' body surface area, intravenous line insertion as well as central venous devices assessment, monitoring of drug adverse reaction and interaction and also participation in cancer research. The Oncology Nursing Society (ONS) has established competencies for oncology clinical trial nurses, ${ }^{[27]}$ oncology nurse navigators, ${ }^{[28]}$ and oncology nurse generalists. ${ }^{[17]}$ In addition, ONS has formed leadership competencies to address the leadership skills and knowledge required at all levels of oncology nursing practice. ${ }^{[29]}$ However, results from the preset study showed that the nurses were most skilled and competent in psychological and spiritual care, self-breast examination followed by oncology pain and symptoms management. The nurses were most poorly skilled and non-competent in reconstituting and administration of IV cytotoxic drugs, screening for pap smear, Clinical breast examination, mammography and obtaining sample for genetic testing. Also, $60 \%$ of the respondents rate themselves generalists in oncology. This is evidenced by the lack of formal training for nurses working in oncology units; hence there is a need to set standards of operation for nurses working in oncology units by establishing minimum competencies to be gained in order to be better able to manage.

Results from the study also indicate that $26.6 \%$ of the participants stated that nurses need to be prepared at the Masters level. This is especially relevant as nurses in all aspects of oncology have an important role to play in the delivery of effective cancer management. ${ }^{[30]}$ Studies have shown that high level of nurses' education results in decreased hospital mortality and ${ }^{[31]}$ improved outcomes. The need for more qualified personnel and quality training programmes are therefore necessary. However, $98.1 \%$ believe NMCN should conduct certification examinations for nurses. Specialty certification in cancer care has the potential to improve the quality of care for patients living with cancer. ${ }^{[31]}$ Also, oncology nursing in the western countries has been transformed to tumor specific cancer nursing. For example, in England, the best practice guideline in cancer requires that all cancer patients have access to a specialist nurse such as the tumor specific clinical nurse specialist. ${ }^{[32]}$ This role has become essential in providing diverse and holistic care, meeting information needs, symptoms control, managing care, and providing psychological and social intervention including referral to other advanced specialists. Thus, these preparations are more robust and hence improves the nurses' practice. The preparation of these specialists at advanced levels such as Masters level is paramount to realize the many benefits that may accrue from training of specialist oncology nurses.

Further challenges found to affect the state of oncology nursing in Nigeria include, inadequacy of schools for training and lack of funds. Moreover, there are few oncology nurse specialization programs available in developing countries and a lack of faculty to teach in such programs. ${ }^{[33]}$ Oncology nurses in developing countries often rely primarily on on-the-job training and rotation through the oncology unit, limiting their experience in oncology. ${ }^{[1,13,34-36]}$ Data from the World Health Organization (WHO) indicates that the response to the cancer epidemic in sub-Saharan Africa has been affected by lack of funds and inefficiency in health systems. ${ }^{[37]}$ Findings from the study of Edward and Colleagues indicates that as a result of challenges that stem from the pyramid of power; lack of resources, mentors, and subject matter experts; there is limited oncology education and training opportunities; and lack of funding. This is also similar to the findings of Malvarez and colleague ${ }^{[38]}$ in which they found that nurses often obtain little to no oncology training in their basic nursing education program. All these findings therefore support findings from this present study.

Other factors found to affect the state of oncology nursing in Nigeria include: lack of oncology facilities, lack of funding of cancer treatment by government and donor agencies, and non-availability of man-power. ${ }^{[39]}$ According to WHO estimate in 2011, the world's health workforce faced a shortage of 2.4 million doctors, nurses and midwives. This shortage is inclusive of oncology trained specialists, and the nursing educational system is faced with several challenges to develop a larger oncology nursing workforce. ${ }^{[13,39]}$ Globally, government spending on health professional education amounts to $\$ 1$ billion, representing $1.8 \%$ of total expenditures on health. This deficit leaves few advanced practice or doctoralprepared nurses as faculty in oncology nursing education programs, or to implement evidence-based practice changes, with notable exceptions in Saudi Arabia. ${ }^{[40,41]}$ In April 2001, African Heads of State met in Abuja, Nigeria and resolved to allot at least $15 \%$ of their annual revenues to health as part of the Millennium Development Goals. Ten years after this agreement, only one country had attained the target, three other countries are making progress to achieve this goal, while the rest have no or insufficient progress. These are the diverse issues that will need to be resolved in order to ensure oncology nursing finds its place in Nigeria. Providing nurses with improved access to information, training, and recognition of specialization could be a major advance in several developing nations, which serve extremely large numbers of cancer patients. ${ }^{[26,42]}$ 
Respondents pointed provision of more training centres/institutions, enlightenment/ awareness, as well as sponsorship for training as ways oncology nursing can be improved in their institution. ${ }^{[43]}$ Callaghan and Colleagues stated that in order for developing countries to benefit from oncology expertise, there is a need to have adequate capacity for the nursing workforce educating nurses in cancer care initiatives, expanding the scope of nursing practice, and increasing task sharing. Therefore, all stakeholders involved in cancer control, treatment, education, and research (ie., Ministries of Health and Education, Nongovernmental Organizations, funders, cancer advocates) must include a scale-up of oncology nursing in developing countries national and regional cancer control planning.

\subsection{Implication to nursing education, practice and re- search}

The current study identifies the needs for urgent establishment and development of training institutions for oncology nursing in Nigeria in order to respond to the increasing cancer burden. The study also highlighted the need of nurses working in oncology units and wards to be properly educated in order to enhance the health of people living with cancer. Furthermore, there is need to incorporate basic cancer contents into the basic nursing curriculum in Nigeria to enhance the understanding of the upcoming nursing professionals on cancer care and its management, which will provide a foundation for preparing a nursing workforce in caring for individuals living with cancer ensuring their optimal quality, safety, and clinical outcomes.

Organizations and health care institutions that are stateowned or federal tertiary health institutions should be ready to sponsor nurses working in oncology units for oncology nursing specialty training thus increasing the number of nurses' workforce in cancer care. Individually nurses in oncology care in Nigeria should undertake a wide range of online oncology courses, some of which are offered free to build their capacity. Academic departments of nursing should seek collaboration with oncology established nursing institutions, outside Nigeria for collaboration in capacity building of faculty and students for oncology research, education and expert service delivery.

Nursing and Midwifery Council of Nigeria (NMCN) should organize a continuing education programme for nurses working in the oncology wards and units in order to inform them of current trends in the management of patients living with cancer, which can also help in building their confidence and skills, ultimately enhancing the quality of life of individuals living with cancer. This report should empower the NMCN to continue its educational reform drive that will ensure a competency based proogramme /curriculum is developed and used to prepare clinical nursing experts including those for oncology care at post graduate levels.

\subsection{Recommendations}

Nurses in Nigeria should also be given the opportunity to specialize in cancer nursing as other cancer specialties and be allowed to go for training in other countries. More grants should be available for oncology nurses researchers in the area of capacity building in cancer care. The government and international agencies should ensure the establishment of University-based training in oncology nursing. The government should have a policy that help in the establishment of oncology training programme for nurses.

\section{Conclusion}

Oncology nursing specialty has found its place in many advanced countries. With the menace of cancer in Nigeria continuing at a great pace, posing a huge burden on the already deficient health care system in Nigeria, and causing destructive tendencies in family life, there comes a greater need to have more established programmes especially at the higher educational level to train professional nurses as specialists in oncology nursing. This hopefully will go a long way to change the present poor state of oncology nursing practice and improve positive patient outcomes in Nigeria. Nigerian nurses working in oncology units therefore need to take an active, participative role in initiating preventive programs for cancer.

\section{Conflicts of Interest Disclosure}

The authors declare that there is no conflict of interest.

\section{REFERENCES}

[1] World Health Organisation. The Abuja declaration: 2018 https://www . who.int/healthsystems/publications/abu ja_declaration/en/

[2] Nigeria National Cancer Control Plan 2018-2022. Federal Ministry of Health Abuja; Nigerian Urban Reproductive Health Initiative. 2019.
[3] Global Burden of Disease Risk factors collaborations. Global regional and national comparative risk assessment of 79 behavioural, environmental and occupational and metabolic risks or clusters of risks 1990-2015; A systematic analysis for the Global Burden of Disease Study 2015. Lancet. 2016; 388(10053): 1659-1724.

[4] Makumi D. Cancer nurses in Africa finding their footing Asia Pac J Oncol Nurs. 2017; 4(1): 4-5. PMid: 28217723 https : //doi10.41 
03/2347-5625.199082

[5] Nwozichi CU, Ojewole F, Oluwatosin AO. Understanding the challenges of providing holistic oncology nursing care in Nigeria. Asia Pac J Oncol Nurs. 2017; 4(1): 18-22. PMid:28217725 https: //doi.10.4103/2347.5625.199074

[6] Nursing and Midwifery Council of Nigeria Accreditation Team, 2019.

[7] Stefan DC, Elzawawy AM, Khaled HM, et al. Developing cancer control plans in Africa: Examples from five countries. Lancet Oncol. 2013; (14): 189-95. https://doi.org/10.1016/S1470-2 045 (13) $70100-1$

[8] Connor SR, Bermedo MC, editors. Global Atlas of Palliative Care at the End of Life. 2019. Available from: http://www. thewhpca.o $\mathrm{rg} / \mathrm{resources} / \mathrm{globalatlasonendoflifecare11}$

[9] American Cancer Society. Cancer in Africa. Atlanta: American Cancer Society. 2011; 1-15.

[10] International Society of Nurses in Cancer Care. ISNCC Cancer Nursing Education Position Statement. 2015.

[11] Watts R, Botti MA, Hunter M. Nurses' Perspectives on the Care Provided to Cancer Patients. Cancer Nursing. 2010; 33(2): E1-8. PMid:20142746 https://doi.org/10.1097/NCC.0b013e3181 b5575a

[12] Jenerette C, Leak A. The role of oncology nurses in the care of adults with sickle cell disease. Clin J Oncol Nurs. 2012; 16: 633-5. PMid:23178356 https ://doi.org/10.1188/12.CJO N. 633-635

[13] Quinn A. Expanding the Role of the Oncology Nurse. Biomedical Imaging and Intervention Journal. 2008; 4(3): e34. PMid:21611002 https://doi.org/10.2349/biij.4.3.e34

[14] Mick J. Factors affecting the evolution of oncology nursing care. Clin J Oncol Nurs. 2008; 307-13.

[15] Anarado AN, Ezeome ER, Ofi OB, et al. Experiences and desired nursing assistance of women on out-patient breast cancer chemotherapy in Southeastern Nigeria. Psycho Oncology. 2015; 26(3): 385-391. PMid:26585674 https://doi.org/10.1002/pon. 4034

[16] University College Hospital, Ibadan. Available from: http://en.w ikipedia.org/uch

[17] Oncology Nursing Society: How oncology Nursing Research impacts healthcare policy. 2016. Available from: https://voice.ons.org/adovacy

[18] Strother RM, Asirwa FC, Busakhala NB, et al. AMPATH Oncology: A model for comprehensive cancer care in Sub Sahara Africa. J Cancer Policy. 2013; 1: e42-8. https ://doi.org/10.1016/j.jcpo .2013 .06 .002

[19] Galassi A, Challinor J, et al. Strengthening the Oncology Nursing Workforce in Low- and middle income Countries to address the growing cancer burden. Lancet Oncology. 2016; 16(8): 887-888. https://doi.org/10.1016/S1470-2045(15)00144-8

[20] Nwozichi CU. Why are chemotherapy errors not reported? Perceptions of oncology nurses in a Nigerian tertiary health institution. Asia Pac J Oncol Nurs. 2015; 2: 26-34. PMid:27981089 https://doi.org/10.4103/2347-5625.152403

[21] Nursing World Nigeria: Federal Government Set to Establish Schools of Oncology and Palliative Nursing. Article Posted on February 8, 2012. Available from: http://www.nursingworldni geria.com/2012/2/fg-set-to-establish-schools-of-o ncology-and--palliative-nursing-in-nigeria

[22] Farmer P, Frenk J, Knaul FM, et al. Expansion of cancer care and control in countries of low and middle income: A call to action. Lancet. 2010; 376: 1186-93. https://doi.org/10.1016/S014 $0-6736(10) 61152-X$

Published by Sciedu Press
[23] Hanna T, Kangolle A. Cancer control in developing countries: Using health data and health services research to measure and improve access, quality and efficiency. BMC Int Health Hum Rights. 2010; 10:24. PMid: 20942937 PMid:20942937 https ://doi .org/10.1 186/1472-698X-10-24

[24] Day SW, Jose G, Federico A, et al. A Sustainable Model for Pediatric Oncology Nursing Education in Low-income Countries. Pediatric Blood \& Cancer. 2012; 58(2): 163-166. PMid:22102623 https://doi.org/10.1002/pbc. 24007

[25] Conter V, Roberto P, Erica B, et al. 2The Role of Twinning Programs and Telemedicine in Pediatric Oncology. In Pediatric HematologyOncology in Countries with Limited Resources. Springer. 2014; 25 35. https://doi.org/10.1007/978-1-4614-3891-5_4

[26] Cleary J, Henry D, Sandra RD, et al. Supportive and Palliative Care for Metastatic Breast Cancer: Resource Allocations in Low-and Middle-Income Countries. A Breast Health Global Initiative 2013 Consensus Statement. The Breast. 2013; 22(5): 616627. PMid:23972474 https://doi.org/10.1016/j.breast.2 013.07 .052

[27] Oncology Nursing Society. Oncology clinical trials nurse competencies 2016. https://www.ons.org/practice-resources/c ompetencies

[28] Oncology Nursing Society. The ChemoSafe Program https : //www . ons . org/newsroom/news/chemosafe-program-aims-stren gthen-access-cancertreatment-sub-saharan-africa

[29] Oncology Nursing Society. Oncology Nursing Society leadership compotencies,2012. Available from: https://www.ons.org/pr actice-resources/competencies

[30] Aiken LH, Cimiotti JP, Sloane DM, et al. The Effects of Nurse Staffing and Nurse Education on Patient Deaths in Hospitals with Different Nurse Work Environments. Medical Care. 2011; 49(12): 1047. PMid:21945978 https://doi.org/10.1097/MLR.0b013e $3182330 \mathrm{~b} 6 \mathrm{e}$

[31] Kendall-Gallagher D, Aiken LH, Sloane DM, et al. Nurse Specialty Certification, Inpatient Mortality, and Failure to Rescue. Journal of Nursing Scholarship. 2011; 43(2): 188-194. PMid:21605323 https://doi.org/10.1111/j.1547-5069.2011.01391.x

[32] Leary A, White J, Yarnell L. The work left undone. Understanding the challenge of providing holistic lung cancer nursing care in the UK. Eur J Oncol Nurs. 2014; 18: 23-8. PMid:24246444 https://doi.org/10.1016/j.ejon.2013.10.002

[33] Morrissey LM, Challinor EB, Colleen N. Nursing care of Children with Cancer. In Pediatric Hematology-Oncology in Countries with Limited Resources. Springer. 2014; 159-180. https: //doi.org/10.1007/978-1-4614-3891-5_13

[34] Price R, Orgoi S, Chadraabal U. Improving Surgical Care in Mongolia: A Model for Sustainable Development. World Journal of Surgery. 2013; 37(7): 1492-1499. PMid:22941237 https ://doi .org/10.1 $007 / \mathrm{s} 00268-012-1763-1$

[35] Akhigbe AO, Omuemu VO. Knowledge, Attitudes and Practice of Breast Cancer Screening among Female Health Workers in a Nigerian Urban City. BMC Cancer. 2009; 9(1): 203. PMid:19555506 https://doi.org/10.1186/1471-2407-9-203

[36] Andsoy II, Gul A. Breast, cervix and colorectal cancer knowledge among nurses in Turkey. Asian Pac J Cancer Prev. 2014; 15: 2267 72. PMid:24716968 https : //doi .org/10.7314/APJCP . 2014.1 5.5.2267

[37] Edwards N, Webber J, Mill J, et al. Building capacity for nurseled research. Int Nurs Rev. 2009; 56: 88-94. PMid:19239521 https://doi.org/10.1111/j.1466-7657.2008.00683.x

[38] Malvarez SM and Agudelo MC 2005. "Overview of the Nursing Workforce in Latin America. 2005. 
[39] WHO Global code of practice on the international recruitment of health personnel. World Health Organization, Geneva; 2011https : //www.who.int/hrh/migration/code/full_text/en/

[40] Almalki M, FitzGerald G, Clark M. The nursing Profession in Saudi Arabia: An overview. International Review. 2011; 53(3): 304-311. PMid:21848775 https://doi.org/10.1111/j.1466-7657.20 $11.00890 . x$

[41] Sheldon LK, Brant J, Hankle KS, et al. Promoting cancer nursing education, training, and research in countries in transition. in: Silbermann M Cancer care in countries and societies in transition. Springer; Cham: 2016. https://doi.org/10.1007/978-3-319
$-22912-6 \_31$

[42] Challinor JM, Hollis R, Freidank C, et al. Educational Needs and Strategies of Pediatric Oncology Nurses in Low- and Middle-Income Countries: An International Society of Pediatric Oncology Pediatric Oncology in Developing Countries Nursing Working Group Initiative. Cancer Nursing. 2014; 37 (4): E36-47. PMid:24201314 https://doi.org/10.1097/NCC. 0000000000000100

[43] Callaghan M, Ford N, Schneider H. A systematic review of taskshifting for HIV treatment and care in Africa. Hum Resour Health. 2010; 8: 8-16. PMid:20356363 https://doi.org/10.1186/14 78-4491-8-8 